\title{
As relações com a produtividade 0 caso do serviço de informações telefônicas
}

\author{
ISABEL GEORGES
}

RESUMO: O artigo discute a construção da noção de produtividade no sistema de serviços de informações telefônicas na França. Para isso, aborda a atual reorganização técnica e espacial do serviço, a formalização de suas atividades, as práticas administrativas das chefias e as práticas de trabalho das operadoras, confrontando diferentes possibilidades de definição do serviço prestado e, portanto, de sua 'produtividade'.

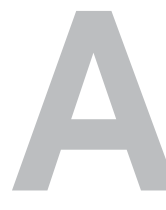

análise do determinismo técnico do trabalho em suas diversas facetas é uma questão clássica em sociologia do trabalho ${ }^{1}$. Em compen-sação, o papel da técnica é muito menos estudado no que concerne às atividades de serviço (cf. Grafmeyer, $1992 \mathrm{e}$ Verdier, 1980), principalmente pelo viés das práticas de trabalho efetivas dos agentes (cf. Alonzo, 1998). Ora, definida como uma maneira dos gerentes intervirem no conteúdo do trabalho, a técnica implica diretamente as definições da produtividade. As relações dos diferentes atores com a produtividade e com o serviço prestado (cf. Gadrey, 1994, 1996) constituem uma das determinações centrais do trabalho estudado: o serviço de informações telefônicas de uma grande empresa de telecomunicações em situação de monopólio sobre a telefonia até o final dos anos $1990 .^{2}$ As operadoras do serviço de informações ${ }^{3}$ fornecem por telefone informações refe-
PALAVRAS-CHAVE:

trabalho, serviços, produtividade.

Pós-doutoranda no CEBRAP 
${ }^{1}$ Como exemplo, podemos citar Akrich, 1990; Braverman, 1974; Charron, 1995; Freyssenet, 1984, 1990, 1992; Maurice, 1980; Stroobants, 1991; Terssac, 1992; De Montmollin \& Pastré (coords.), 1984; Número especial de Sociologie du travail, 4/84, "Nouvelles technologies dans l'industrie", Hors série 1994, "Les énigmes du travail".

${ }^{2}$ Este artigo é tirado de uma tese de Sociologia (Georges 2000a), realizada sob a orientação científica de Margaret Maruani no quadro de uma convenção Cifre (Convention industrielle de formation par la recherche) com a France Télécom, entre 19961999. Trata-se de uma versão modificada de Georges, 2000b.

3 Trata-se de mulheres, em $70 \%$ dos casos, e de uma ocupação tipicamente feminina, razões pelas quais foi escolhido o plural feminino.

${ }^{4}$ Em matéria de "serviço público das telecomunicações", a lei em vigor, publicada em 27 de julho de 1996, estipula, no artigo L. 35-4: "Estão postos à disposição do público, um anuário universal, na forma impressa e eletrônica, assim como um serviço universal de informações. Sob reserva da proteção dos direitos das pessoas concernidas, eles dão acesso aos nomes e razões sociais, às coordenadas telefônicas e aos endereços de todos os assinantes nas redes abertas ao público, assim como à menção de sua profissão para os que o desejarem". rentes ao nome, endereço, razão social e número de telefone dos assinantes de telefone fixo, com o auxílio de utensílios microinformáticos.

As relações com a produtividade fazem aparecer a tensão entre o serviço prestado pelas operadoras e as exigências da empresa. Com sua privatização, a produtividade se tornou novamente um centro de preocupações para os gerentes: o serviço das informações telefônicas tornou-se objeto de uma reorganização técnica e espacial, sem que por isso perdesse sua missão de serviço público. ${ }^{4}$ Com efeito, uma concepção universalista da produtividade, veiculada pela chefia, se opõe, em certos casos, a uma concepção local da produtividade, veiculada pelos coletivos de operadoras.

Este texto propõe uma análise das relações com a produtividade de várias categorias de pessoas no interior da empresa: tal relação é definida como um mecanismo de diferenciação social das pessoas em interação. A atividade das operadoras é avaliada socialmente pelos diferentes atores em interação quando de sua realização: o valor social do grupo das operadoras é mediatizado através de sua atividade. Ao privilegiar o ponto de vista das operadoras, a análise mostra as maneiras pelas quais elas contribuem para criar sua própria atividade. Isso quer dizer que as operadoras dispõem de um poder de definição de sua atividade que pode variar segundo os lugares e a história de cada centro de informações ( $C R T)$, o que permite que se apropriem da definição do serviço prestado. Elas emitem um juízo social sobre o serviço, por ocasião de cada interação, e ao se referirem à sua definição de um "espírito do serviço público à francesa”. No entanto, cada interação desenrola-se em um quadro sociotécnico definido particularmente pela chefia. Tais "formas sociais de automação" (cf. Freyssenet, 1992) desempenham um papel nas condições de realização de trabalho efetuada nos centros, isto é, nas relações com a produtividade. Estas últimas constituem um dos elementos que influenciam a qualificação social dessa categoria profissional, ou seja, seu valor social. Com isso, participam da configuração coletiva do grupo das operadoras.

Como a reorganização sociotécnica do trabalho afeta o conteúdo do trabalho das operadoras? Isto é: de que maneira ela age sobre a produtividade do trabalho? Do ponto de vista dos diferentes coletivos de operadoras nos centros de informação, o conteúdo de seu trabalho apresenta-se todavia de maneira homogênea? Existe na prática, com efeito, uma definição uniforme do serviço prestado? Como é socialmente construída a produtividade dessa atividade de serviço?

A partir de uma perspectiva inicial do trabalho rotineiro da operadora, a análise mostrará as transformações do conteúdo do trabalho das operadoras no contexto de sua reorganização (A) e as práticas coletivas no interior dos centros locais (B).

O procedimento adotado consiste em multiplicar os pontos de vista sobre a atividade. A análise repousa em um estudo conduzido por meio de conversas e observação. Documentos de arquivo e notas de serviço foram igualmente consultados. Na França, aproximadamente trinta entrevistas 
semidirecionadas foram realizadas com operadoras de serviços de informações telefônicas, referindo-se à sua trajetória socioprofissional. Elas se desenrolaram nos centros de informação (CRT) durante o tempo de trabalho. Observou-se o trabalho da operadora. ${ }^{5}$ Foi realizada uma pesquisa em oito centros de informação, situados em diferentes regiões, em Paris, na periferia e no interior do país. Meu estatuto de estudante-estagiária no interior da empresa me permitiu, essencialmente, ter acesso aos pontos de vista dos gerentes da atividade. $\mathrm{O}$ período de pesquisa coincide com o período de privatização da empresa. ${ }^{6}$

Na França, o serviço de informações telefônicas era uma das atividades femininas situadas abaixo da escala das classificações do gerenciamento do Serviço de Correios e Telecomunicações $(P T T) .{ }^{7}$ As operadoras de telefone eram recrutadas por concurso em que se avaliavam conhecimentos gerais, antes de iniciar carreira de serviço geral não técnico. ${ }^{8}$ Atualmente, o serviço continua sendo prestado por operadoras titulares. $90 \%$ delas têm o estatuto de funcionário. Entretanto, desde a reforma dos estatutos de 1993, as operadoras do serviço de informações são recrutadas e alocadas em um posto que traz o título de operadora. Na escala de classificações, o posto de "operadora no serviço de informações telefônicas" aparece no nível 1.3., isto é, no mais elevado escalão da categoria situada na escala inferior (a que vai no máximo até o nível 4). Essa mudança é acompanhada por uma mutação nos modos de gerenciamento das carreiras dos agentes. O serviço prestado é afetado principalmente pela reorganização e formalização da atividade.

O trecho abaixo de uma interação sem face-a-face entre a operadora e o utilizador ${ }^{9}$ oferece um exemplo dos mal-entendidos com que a operadora depara-se por ocasião do exercício cotidiano de sua atividade. A análise faz com que apareçam os tipos de iniciativa intelectual necessária para que a busca seja bem sucedida: às vezes, é necessário perseguir várias pistas de busca, elaborando astúcias do ofício (o conhecimento técnico da operadora, sua cultura geral, como o conhecimento das instituições, por exemplo, e sua capacidade de dedução). Anteriormente, como agora, o trabalho rotineiro da operadora consiste em comparar informações do senso comum, não classificadas e não ordenadas, com categorias administrativas pré-codificadas. Trata-se de um trabalho de categorização, decodificação e tradução de informação não classificada, ou seja, trata-se do domínio de técnicas de organização.

Um homem idoso procura o número telefônico de um fundo de pensão complementar da marinha nacional. Não dispõe nem da denominação exata do organismo procurado, nem do estatuto do assinante (um particular, uma empresa ou um serviço oficial). A operadora acaba encontrando a informação por associação de idéias. Em cada passo da busca, ela compõe um quadro com as possibilidades técnicas da estação de trabalho. ${ }^{10}$

\section{Primeira sequência}

Um homem idoso solicita "a torre ENIM em Saint-Malo".
${ }^{5}$ Usei um fone de ouvido que me permitiu escutar as conversas entre a operadora e o utilizador do serviço, observando, ao mesmo tempo, as manipulações efetuadas sobre o teclado e o que aparecia na tela do computador.

${ }^{6}$ Período durante o qual a empresa levou adiante o projeto de "modernização do serviço de informações telefônicas".

${ }^{7}$ Devido à falta de espaço, não foram tratados neste artigo aspectos estatutários. $\mathrm{O}$ leitor interessado pode se remeter a Georges, 2001.

${ }^{8} \mathrm{Na}$ maior parte das vezes, às operadoras de telefone fora conferido o grau de agente de exploração $(A E X)$, pertencente à categoria $\mathrm{C}$ da função pública.

9 Sobre o emprego do termo "utilizador", cf. nota 13 deste artigo.

${ }^{10}$ A estação de trabalho, isto é, os postos de trabalho individuais, a organização da base de dados, o software de busca, assim como a organização entre os diferentes centros de informação telefônica foram renovados em 1997. 


\section{Primeira busca}

A operadora lhe pergunta se busca uma companhia de seguros, enquanto ela está olhando na lista "negócios" (um dos critérios de busca do software empregado é o estatuto do assinante: particular, negócios ou serviço oficial) e na lista de nomes (um critério de busca obrigatório, neste caso, a sigla). A mensagem que figura na tela (o resultado da busca) é um endereço, porém, em "lista vermelha" (isto é, com o endereço do assinante, mas sem o seu número de telefone, já que este solicitou para não figurar no anuário). Em seguida, a operadora lhe pergunta se ele deseja obter a Seguridade Social, mas não é isso que ele busca.

\section{Segunda busca}

Ele pede "a coisa [truc] para os marinheiros".

Com o endereço obtido pela operadora através da inscrição em lista vermelha, ela efetua uma busca por "rua" (sem distinção da rubrica, isto é, sem o estatuto do assinante).

\section{Segunda seqüência}

\section{Terceira busca}

Ela busca novamente usando a sigla, mas na rubrica "serviços oficiais".

\section{Quarta busca}

Em seguida, ela muda a sigla empregando o termo "negócios marítimos" (no campo nome), ainda na mesma rubrica "serviços oficiais", e encontra a informação. Tratava-se, afinal, de um fundo de pensão complementar para a Marinha nacional.

\section{Primeira seqüência}

A primeira tentativa da operadora visa a efetuar uma busca da maneira mais precisa possível, empregando diretamente a sigla fornecida pelo utilizador (de resto, é preciso saber se se trata de uma sigla ou de um nome próprio). Ela efetua então um teste para saber se há um profissional com esse nome (na lista "negócios").

Obtém uma resposta (um endereço), porém, não unívoco: com efeito, são numerosos os casos em que a mensagem "lista vermelha" significa que a inscrição teve lugar sob outra denominação.

Uma primeira tradução transformou o que no início era uma informação meta (o nome, sem precisão suplementar acerca da categoria na qual ingressa seu portador, ou seja, seu estatuto exato) em informação aberta (a rua). Isso quer dizer que, com o novo sistema de exploração, uma busca com o endereço, por meio da "rua", é a única capaz de oferecer um conjunto de inscrições não discriminadas segundo o seu estatuto (empresa, particular, etc.). Ciente disso, a operadora segue esta pista até o fim. Ora, sem infor- 
mações complementares (do utilizador), ela não obtém nada na longa lista de possibilidades: nada parece convergir com outro critério de discriminação, ainda que vago (semelhança com um organismo de seguros, por exemplo).

Ela propõe outra coisa ao utilizador (a seguridade social é fácil de encontrar, pois existe até mesmo uma tecla pré-codificada), para tentar identificar o tipo de organismo que o homem procura. Mas ainda não é disso que se trata exatamente.

\section{Segunda seqüiência}

Então ela muda de tática e decide proceder ao "caso a caso", isto é, efetuar buscas restritivas uma a uma (a busca que tem o estatuto de "serviços oficiais", com a sigla que ela acredita ter compreendido).

Finalmente, ela encontra, por meio de uma associação de idéias com algo que o utilizador lhe disse ("a coisa para os marinheiros"), um termo que parece corresponder ao organismo que o utilizador busca (um fundo de pensão complementar da marinha).

Como a operadora notou que se tratava de um senhor idoso, que não sabia se exprimir, ela prosseguiu e efetuou quatro buscas. A cada vez, ela (re)compõe os critérios da busca, simultaneamente propõe e solicita informações complementares ao utilizador. Ela assimilou a finalidade do serviço prestado: dar assistência a uma pessoa idosa. O estabelecimento dessa relação não mercantil lhe permitiu, entretanto, valorizar-se socialmente.

Importa atentar para o número de aproximações, ampliações e restrições, assim como para o avanço da busca mediante a exclusão de possibilidades: tais práticas implicam um certo tempo. A duração mais ou menos longa dessas diferentes operações, que traduz táticas de busca, está relacionada à "produtividade" das operadoras: aos olhos de certos membros da chefia, a quantidade de chamadas tratadas define o rendimento do pessoal de execução. Com efeito, a partir de uma vaga demanda inicial, a realização de uma busca não é algo evidente: ela reflete um certo estado das relações sociais naquele centro a partir do qual se desenrola essa interação. Nesse centro, a definição social da "produtividade" comporta a transmissão de um conhecimento em meio a um pessoal composto exclusivamente por titulares. Em compensação, o conteúdo e a duração dessas práticas de busca dependem igualmente das formas sociais de automação: qual é então a influência das transformações do conteúdo do trabalho sobre as relações com a produtividade?

\section{As transformações do conteúdo do trabalho}

No final dos anos 80 e início dos 90, a organização técnicoespacial do trabalho do serviço de informações telefônicas permite às operadoras assimilar, em larga medida, a finalidade do serviço prestado. Isso 
${ }^{11}$ Tais problemas são inerentes à interação desprovida de face-aface. Podem dizer respeito à fonética: a ortografia da palavra; o contexto geográfico; o funcionamento técnico e jurídico das instituições; a ambigüidade sobre a categoria da palavra (Georges, 1995).

12 Trata-se entretanto de um fenômeno passageiro, inerente ao período de adaptação de ambos os lados à nova organização do serviço.

${ }^{13}$ Termo utilizado aqui de maneira genérica em relação à diferentes formas de "clientela". Em francês, contrariamente ao emprego anglo-saxão, esse termo está carregado de uma certa conotação, que nesse contexto o oporia principalmente a usager (sub-entendido: o de um serviço público). Para evitar esse gênero de referências ideológicas subjacentes, emprego geralmente o termo "utilizador". quer dizer que, por ocasião do aparecimento de problemas de comunicação entre a operadora e o utilizador do serviço, ${ }^{11}$ a organização do trabalho e os meios técnicos disponíveis permitem às operadoras adaptar o serviço à demanda. Como tal trabalho de tradução e de pesquisa implica um certo tempo, as operadoras definem em parte a produtividade do serviço. O serviço prestado pelas operadoras e o dispositivo técnico em "livre serviço", o Minitel-ou o anuário eletrônico - estão de fato em situação de concorrência. A análise mostra como a reorganização técnica e espacial do serviço de informações, instalado no contexto da privatização, restringe a margem de manobra das operadoras e intervém nas relações com a produtividade.

A reorganização do serviço concerne principalmente à divisão do trabalho entre os centros e os postos individuais de trabalho, em particular pela mudança do software de pesquisa, e por um controle informático do rendimento que pode ser mais constrangedor.

A divisão do trabalho entre os centros, isto é, a repartição das chamadas, se desdobra em três niveis: no interior de cada centro individual, no interior de sub-redes compostas por dois ou três centros individuais e no interior de uma rede que liga o conjunto dos centros entre si (ver o gráfico abaixo). Os centros individuais (cerca de cem) de porte variável (de 15 a 100 operadoras) não foram modificados. Em compensação, as chamadas provenientes de uma zona geográfica ampliada são distribuídas de maneira equitativa no interior de sub-redes compostas por vários centros. De maneira indiferenciada, elas entram numa fila de espera para o distribuidor de chamadas (o $D A N$ do gráfico) que se situa num dos centros em rede. No interior da rede global, chamadas provenientes de certas regiões geográficas foram deslocadas para outras regiões. Essas transferências foram às vezes acompanhadas por mutações geográficas do pessoal, ou por reconversões do pessoal disponível no local onde a empresa passou a se instalar.

A reorganização técnico-espacial do trabalho entre os centros transforma o serviço prestado: modificou-se o vínculo entre um grupo de utilizadores e as operadoras de um centro de informações particular. Já não podem partilhar as mesmas referências geográficas: o utilizador pode se haver com uma operadora situada em espaço geográfico diferente do seu, e viceversa.

Por conseguinte, de um lado, problemas de comunicação ligados ao contexto geográfico podem aparecer: ${ }^{12}$ o tratamento da demanda exige que se leve em conta particularidades regionais, tais como a ortografia particular dos nomes das comunas na Bretanha, ou ainda, o conhecimento dos homônimos de cidades que existem em várias regiões (por exemplo, Montigny-les-Corneilles no departamento de Val d'Oise e Montigny-leBretonneux situado no departamento de Yvelines, servidas no entanto pelos mesmos centros de informação).

De outro lado, as operadoras encontram maior variabilidade de casos em seu trabalho que, de maneira cada vez mais acentuada, requer um es- 


\section{Mapa das redes de CRTem $1^{\circ}$ de julho de 1998}

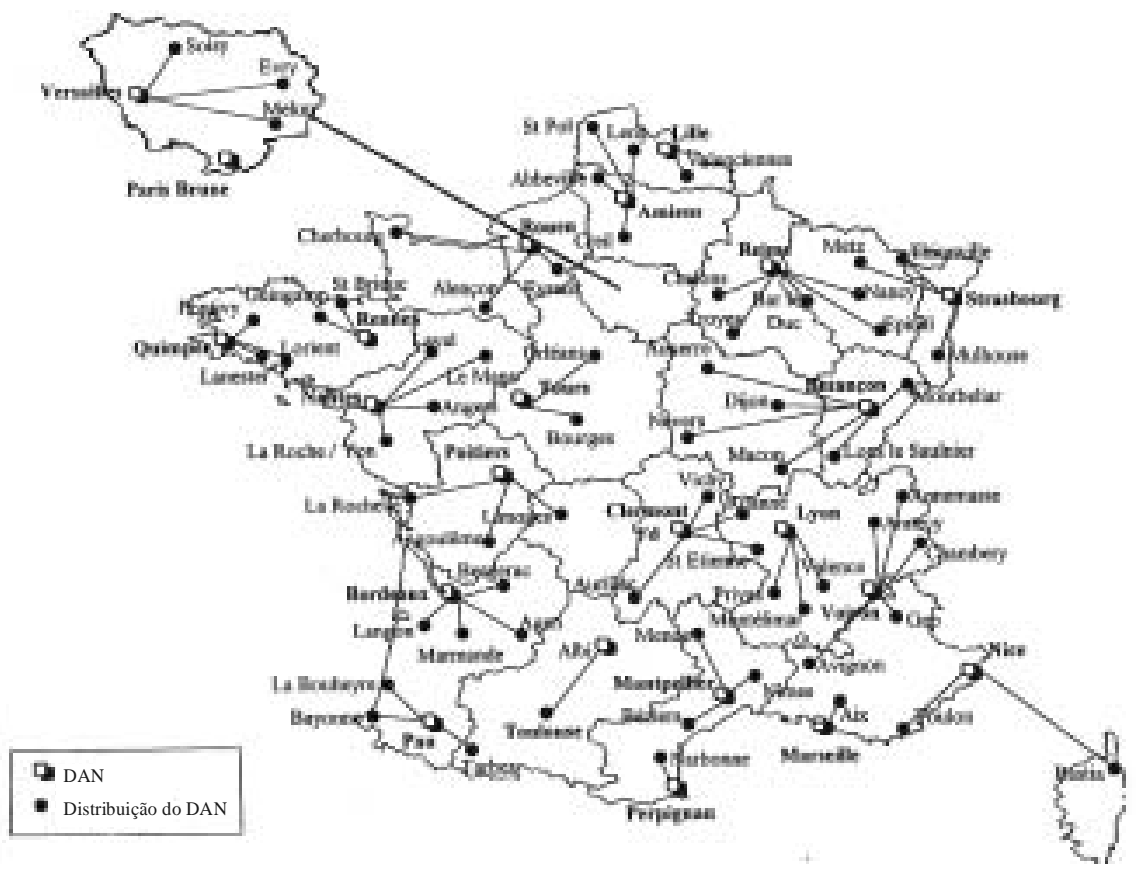

forço de adaptação. Isso quer dizer que as diferentes "clientelas"13 locais têm características sociodemográficas distintas. As operadoras assinalam, por exemplo, uma presença de pessoas idosas mais considerável no departamento de Val d'Oise. Em contrapartida, as chamadas provenientes do bairro parisiense da Défense compreendem uma parte importante de demandas de secretárias ou de homens de negócios, de buscas de sociedades. Ora, tais características implicam modos diferentes de se exprimir e de formular a "demanda". ${ }^{14}$ As secretárias de tais sociedades, por exemplo, formulam a demanda em conformidade com sua definição técnica: são profissionais desse tipo de trabalho e sabem codificá-la (demandas "pré-formuladas"). Em compensação, aqueles (ou aquelas) que não podem (idosos, estrangeiros, pessoas com nível restrito de educação, etc.) ou não querem (membros das categorias socioprofissionais superiores, de certo nível social) formular a demanda de maneira rápida e precisa, se exprimem menos claramente e a elaboram ao longo da interação com a operadora. Tendo aumentado a heterogeneidade da demanda, as operadoras se acham diante de uma escolha: padronizar o serviço prestado ou passar mais tempo para se adaptar a cada caso.

A estação de trabalho inclui também dois níveis: os postos individuais de trabalho propriamente ditos, a organização da base de dados e o software de busca. Em particular, a mudança dos dois últimos elementos

\section{Figura 1}

${ }^{14}$ Emprego aspas porque o uso desse termo faz supor a pré-existência da demanda em relação à interação. Ora, ela resulta da negociação entre a operadora e o utilizador. Um dos critérios que intervém nessa discussão é o grau de préformulação da demanda: ele permite à operadora atribuir um estatuto social ao cliente. 
afeta o modo de busca da operadora.

Primeiramente, alguns critérios de classificação das inscrições de assinantes de telefone na base de dados (por exemplo, nome, prenome, endereço, número), por meio de "listas" (uma "busca por rua" designa, por exemplo, o uso do critério da rua para encontrar as coordenadas do assinante), mudaram de modalidade. Assim, o departamento como referente geográfico foi substituído pela comuna. A mudança da forma de acesso à informação (por exemplo, a ortografia aproximada do nome já não é técnicamente admissível), assim como a hierarquização e a combinação dos critérios de busca no software, é o segundo componente da modernização da estação de trabalho. Inscritas na estação de trabalho, as modalidades técnicas de busca podem constituir uma vantagem para fazer frente aos tipos de mal-entendido com os quais as operadoras se deparam no exercício cotidiano de sua atividade (abordados no início deste artigo), mas também podem obrigar as operadoras a se reorganizar, o que é o caso com a nova forma de automação. ${ }^{15}$ Mostrou-se principalmente que o limiar de tolerância técnica perante o grau de precisão ou imprecisão da informação inicial é menor, desde que foram introduzidas as modificações da estação de trabalho. Ora, o nível de serviço prestado se negocia justamente em função de tais critérios.

A reorganização da divisão do trabalho entre os centros e a modernização do material da estação de trabalho (sobretudo da organização da base de dados e do software de busca) modificaram o conteúdo do trabalho das operadoras: elas produzem um impacto sobre suas relações com a produtividade. O primeiro elemento, a reorganização técnico-espacial do trabalho, equaliza a repartição do volume global de trabalho entre os centros, tendendo a uniformizar os ritmos de trabalho individuais. Com efeito, as operadoras são confrontadas com a escolha entre um sobreinvestimento no trabalho e uma maior padronização do serviço prestado. O segundo elemento as põe em situação análoga: as modificações da estação de trabalho induzem a uma menor flexibilidade técnica do processo da busca. As operadoras são levadas, portanto, a solicitar uma demanda padronizada por parte do cliente, isto é, conforme à prescrição técnica. A ação conjunta desses dois elementos incita as operadoras a reduzir a extensão do serviço prestado: a organização técnica e espacial do trabalho reflete a definição universalista da produtividade, trazida pelos gerentes. A organização técnico-espacial do trabalho contribui fortemente, portanto, para a construção social da produtividade no interior dessa atividade de serviço. Em contrapartida, o que ocorre com as práticas de chefia nos diferentes centros? O conteúdo do trabalho das operadoras chega a se apresentar de maneira homogênea em todos os centros?

15 Ver o quadro resumido dos problemas de comunicação e das soluções técnicas no Quadro 1.

\section{As práticas coletivas no interior dos centros}

As práticas de trabalho das operadoras, isto é, as maneiras 
pelas quais as operadoras abordam a relação com o cliente - e afirmam seu próprio ponto de vista no interior da relação - não dependem somente das formas sociais de automação, mas, igualmente, das práticas administrativas da chefia, o que eu mostro a partir do exemplo de dois centros de informação de tipo oposto, I e II (II corresponde ao exemplo de interação acerca do fundo de pensão dado acima). Os centros do primeiro tipo são majoritários no interior da empresa situada no fim dos anos 90.

Os diferentes centros locais se distinguem entre si por sua duração para realizar tal atividade. Distinguem-se igualmente pelas características mais ou menos estáveis e homogêneas dos fluxos de seu pessoal (de base e de chefia). Os centros I e II se particularizam em dois níveis. O

\section{As "soluções técnicas" para os problemas de comunicação no contexto das duas formas de automação}

\begin{tabular}{|c|c|c|}
\hline $\begin{array}{l}\text { Problemas de } \\
\text { comunicação }\end{array}$ & $\begin{array}{l}\text { A antiga forma de } \\
\text { automação }\end{array}$ & $\begin{array}{l}\text { A nova forma de } \\
\text { automação }\end{array}$ \\
\hline $\begin{array}{l}\text { A referência } \\
\text { geográfica }\end{array}$ & $\begin{array}{l}\text { Referência obrigatória: o } \\
\text { departamento, } \\
\text { possibilidade de indicar } \\
\text { a comuna }\end{array}$ & $\begin{array}{l}\text { Comuna obrigatória, } \\
\text { possibilidade de ampliar } \\
\text { a busca }\end{array}$ \\
\hline $\begin{array}{l}\text { A ambigüidade } \\
\text { sobre a categoria da } \\
\text { palavra; o } \\
\text { funcionamento } \\
\text { jurídico ou técnico } \\
\text { das instituições }\end{array}$ & $\begin{array}{l}\text { Possibilidade de cruzar } \\
\text { uma busca profissional e } \\
\text { por nome, sem } \\
\text { diferenciação do } \\
\text { "estatuto" do assinante } \\
\text { (particular, profissional, } \\
\text { serviço oficial) }\end{array}$ & $\begin{array}{l}\text { Obrigação de escolher, } \\
\text { desde o início, uma } \\
\text { "lista" (por nome, } \\
\text { profissão, endereço etc.) }\end{array}$ \\
\hline $\begin{array}{l}\text { A ortografia do } \\
\text { nome; a fonética: } \\
\text { ouvir claramente }\end{array}$ & $\begin{array}{l}\text { Possibilidade de captar } \\
\text { uma ortografia } \\
\text { aproximada (busca } \\
\text { "fonética") }\end{array}$ & $\begin{array}{l}\text { Obrigação da ortografia } \\
\text { exata; busca por "ítem" } \\
\text { (independentementeda } \\
\text { ordem das palavras na } \\
\text { inscrição) }\end{array}$ \\
\hline $\begin{array}{l}\text { A ambigüidade } \\
\text { sobre a categoria do } \\
\text { nome }\end{array}$ & $\begin{array}{l}\text { Busca por rua sem } \\
\text { diferenciação das listas } \\
\text { de assinantes em função } \\
\text { de sua categoria }\end{array}$ & Sem modificação \\
\hline
\end{tabular}




\section{A antiga e a atual forma de automação}

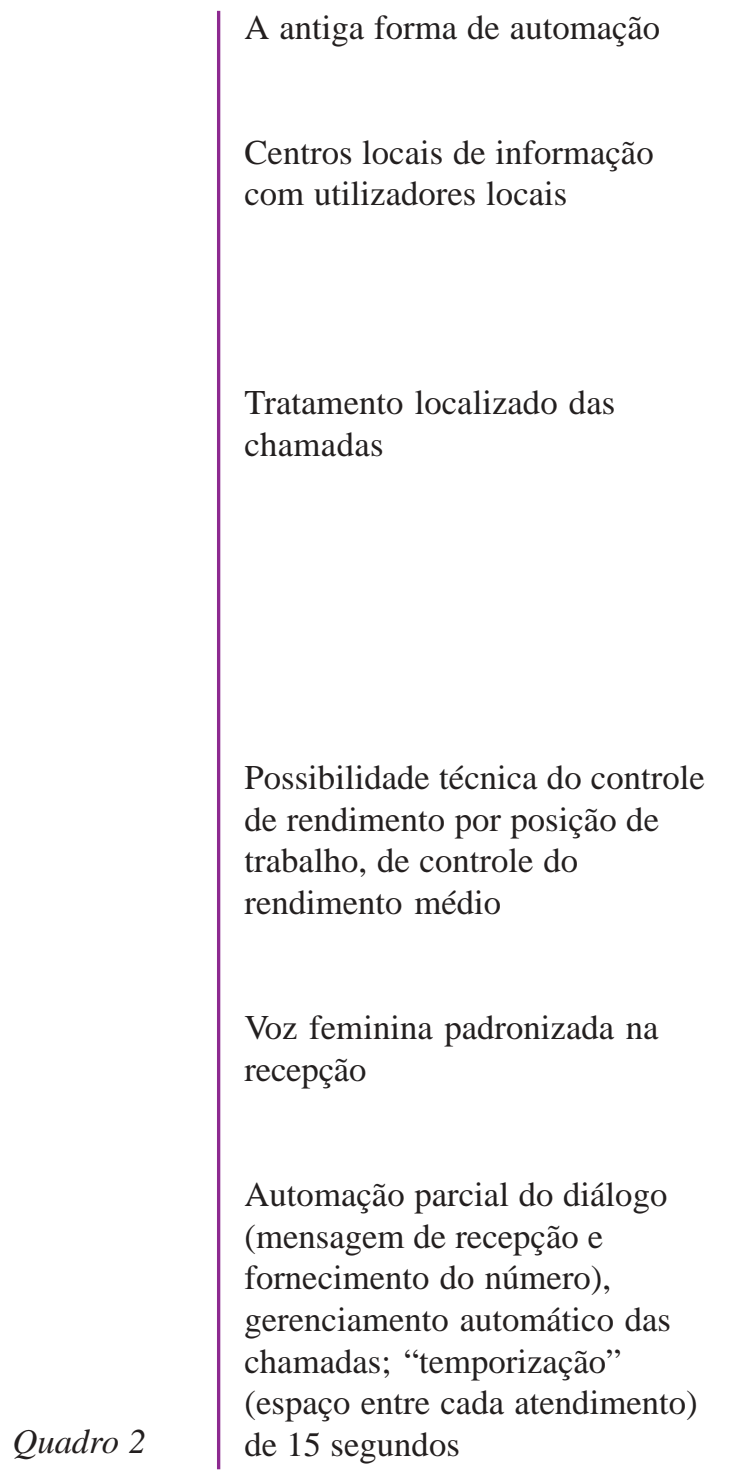

A forma atual de automação

"Posição em rede" de vários centros de informação: ampliação de uma zona geográfica servida por vários centros em comum

Tratamento transversal das chamadas no interior de "redes primárias", possibilidade de transferência de chamadas entre regiões (deslocamentos), sistemática para o tráfego da região de Île de France

Individualização do número de chamadas tratadas, da duração de espera do cliente e do número de transferências

Voz personalizada (do agente) da recepção

Temporização de 5 segundos

primeiro é antigo, ao passo que o segundo foi fundado recentemente, em 1996. No primeiro centro, situado em região parisiense, prevaleceram historicamente fluxos de agentes em começo de carreira. Mais recentemente, parte da chefia é oriunda do setor comercial. O segundo centro resulta da reconversão de um antigo parque industrial em atividades de serviço, conservando o pessoal.

As características dos centros influenciam as condições da divisão do trabalho entre os agentes. Por este viés, elas têm impacto sobre a 
maneira pela qual as operadoras podem apreender a produtividade, isto é, o serviço prestado. Por exemplo, no primeiro centro, a divisão do trabalho está inscrita nos usos que a chefia faz da técnica. A chefia se apropria da definição do objetivo do serviço: a divisão do trabalho é orientada para a obtenção de um rendimento individual (em termos do número de chamadas atendidas). Inversamente, no segundo centro pratica-se uma divisão do trabalho historicamente apegada a uma atividade de reparação técnica (de postos de telefone). Grande parte do pessoal exerceu essa atividade anteriormente, inclusive a chefia. O objetivo comum é a aquisição de conhecimentos pela prática do auxílio mútuo.

A atividade da chefia consiste essencialmente em organizar o trabalho das operadoras, principalmente a divisão do trabalho entre elas. Essa organização é tributária das diferentes práticas de trabalho importadas dos setores de atividade em que anteriormente trabalhara uma encarregada. ${ }^{16} \mathrm{Como}$ já vimos, no primeiro centro, parte desse pessoal veio do setor comercial das agências, ao passo que, no segundo, a totalidade do pessoal de chefia (do chefe do centro passando pela encarregada, incluindo cada uma das operadoras) trabalhou anteriormente no domínio técnico. O pessoal oriundo do setor comercial está mais familiarizado com a definição de serviço que o concebe como um produto, cujo conteúdo se acha antecipadamente predeterminado. A divisão do trabalho que eles implementam parte dessa concepção: no primeiro centro, a chefia individualiza os agentes, ao passo que, no segundo, a chefia, oriunda de um outro setor de atividade, tentou preservar certa maneira de cooperar entendida como fundamento do serviço prestado.

Assim, os centros do primeiro tipo adotaram globalmente uma forma de divisão do trabalho similar, que distribui o pessoal de execução de maneira direcionada, segundo "sua performance", definida pelo rendimento individual em termos de chamadas atendidas. O centro do segundo tipo é o "contra-exemplo" do primeiro, no que respeita à divisão do trabalho.

No centro do primeiro tipo, as operadoras estão distribuídas, segundo seu suposto nível de rendimento individual, em "grupos técnicos": trata-se de grupos de operadoras que podem receber o mesmo tipo de chamada. Um grupo inclui as operadoras que tratam exclusivamente do tráfego do "12" (as informaçõe simples); outro grupo trata também do "3692", isto é, das informações "múltiplas", para as quais as chamadas duram supostamente mais tempo. O primeiro grupo comporta sobretudo jovens e pessoal contratados por tempo determinado; o segundo grupo é o de operadoras mais experientes. Tal organização tende a equalizar o rendimento individual médio, visto que as operadoras com mais desempenho, as que respondem aos dois números, atendem às chamadas do " 12 " mais rapidamente que as iniciantes do primeiro grupo e podem, portanto, atingir uma duração média das chamadas equivalente à desse grupo.

No segundo centro, não há grupos “técnicos”. Todo mundo pode tratar todos os tipos de chamada. Quando têm dificuldades para efetuar a
${ }^{16}$ De um lado, essa renovação do pessoal de chefia está vinculada aos que vão para a aposentadoria e a préaposentadoria (possível a partir de 55 anos desde o dispositivo implementado em 1995), mas é possível que o "projeto de modernização" do "serviço de informações", em curso desde o início dos anos 90, tenha acelerado esse movimento, e mesmo, contribuído para movimentos de populações entre os diferentes domínios de atividade. 
busca, as operadoras perguntam às colegas.

Como vimos, num primeiro momento, as práticas da chefia se referem sobretudo à divisão técnica do trabalho: tentam intervir na margem de manobra das operadoras, organizando os postos de trabalho técnico segundo as capacidades atribuídas às operadoras que os ocupam (principalmente ao distinguir as antigas e as novas pelo tipo de chamadas a atender). A chefia tenta igualmente organizar o trabalho através da distribuição espacial e, principalmente, através da colocação de operadoras nos mesmos postos de trabalho e através da presença física (ou não) da chefia nas salas.

No segundo centro, inversamente que ocorre no primeiro, a chefia exerce raramente uma função de "vigilância" nas salas.

(II) Sobre a posição da encarregada (uma na entrada de cada sala), estatísticas dos agentes estão acessíveis simultaneamente (a duração da chamada em curso figura na tela para todos os agentes, assim como a duração da pausa, se saíram para descanso por exemplo) e em retrospecto. Cada vez que eu entro na sala, não há um chefe no local.

Num segundo momento, é a maneira de ressaltar e de utilizar a "produtividade" que caracteriza as práticas da chefia e o tipo de centro.

Os responsáveis pelos centros, que impõem uma divisão do trabalho relativamente rígida entre as operadoras, são freqüentemente os mesmos que põem em primeiro plano o rendimento individual das operadoras em termos do número de chamadas atendidas. Nesse caso, o serviço é considerado como um produto padronizado e objetivável, sujeito à avaliação pela chefia. Um dos importantes indicadores da concepção do serviço e, ao mesmo tempo, da produtividade é a maneira pela qual esta última é transmitida (ou não) às operadoras. Assim, nos centros do primeiro tipo, o rendimento individual é um elemento do gerenciamento da mão-de-obra, ao passo que a chefia dos centros do segundo tipo não o transmite, ou somente em contextos particulares.

No primeiro centro, onde a idéia de um serviço padronizado é comumente admitida pela chefia, as estatísticas individuais dos agentes e por grupo "técnico" são afixadas na parede do corredor. Integrado nas tarefas da chefia, o técnico do centro tem uma visão ainda mais "tecnicista" do serviço se esta for comparada à da chefia: ele atribui um valor "universal" aos indicadores do rendimento, dissociado das práticas locais. Isso quer dizer que ele considera que é possível comparar o "rendimento" de todos os agentes individuais que trabalham numa mesma sub-rede de centros.

(I) Nesse centro, como nos outros, as estatísticas "de exploração" dos agentes, as que mostram o número de 
chamadas atendidas, sua duração, o número de transferências para outro local, a duração das pausas, a duração para pôr o local em indisponibilidade técnica (corte técnico enquanto, por exemplo, a operadora colhe uma informação) estão disponíveis de maneira periódica (por hora, semanal ou mensalmente, na hora em curso e na hora precedente), tanto no que respeita a um agente individual como a um grupo "técnico" e a um centro. Os agentes de cada local só podem ver as suas estatísticas. Tal configuração foi escolhida para evitar a rivalidade entre os agentes dos diferentes locais situados numa mesma rede. Segundo Luc, o técnico do centro: "Ainda se trabalha com base no corporativismo".

Ele está longe de pôr em questão a definição subjacente do serviço, o qual teria supostamente um conteúdo uniforme, que funda a idéia de que é possível pôr em competição agentes em torno da quantidade de chamadas atendidas. Nesse centro, com efeito, predomina uma competição "universalista" da produtividade: trata-se de uma maneira de tornar comparável o trabalho dos agentes e de um modo de gerenciamento da mão-de-obra.

Para coletar o rendimento individual dos agentes, no centro do segundo tipo, a chefia dispõe das mesmas "ferramentas" no nível informático que as de outros centros, mas essa informação fica reservada à chefia. $\mathrm{O}$ dispositivo técnico é configurado para fornecer de modo padronizado o rendimento coletivo, e não individual.

(II) No posto de supervisão situado na pequena sala de chefia, em frente às duas "salas de exploração", cuja porta fica geralmente fechada quando não há ninguém, as estatísticas são dadas "por grupo". Nesse caso, o grupo inclui o conjunto das operadoras do centro (comparadas com os outros centros da rede). Os números aparecem na tela do computador em cor rosa, passando para a cor vermelha em caso de sobrecarga (excesso de chamadas na espera e duração média de espera prolongada).

Resultante de outro setor de atividade e acostumado a práticas coletivas de trabalho, a chefia considera, inversamente à do primeiro tipo, que o conhecimento mútuo de suas produtividades individuais pode perturbar as boas relações de trabalho, que constituem o objetivo primeiro buscado pela encarregada.

Christophe, um dos encarregados, comenta: "É um pouco incômodo, a gente não quer que eles vejam quem fez isso, quem fez só isso; é melhor que eles nos perguntem". 
Por outro lado, o demonstrativo automático do rendimento individual e personalizado, que se tornou obrigatório com a mudança da estação de trabalho, ${ }^{17}$ não alterou as relações hierárquicas. Ao contrário, a formalização técnica dessa prática de chefia contribui para sua "democratização".

Christophe: "Com o antigo sistema, a gente também tinha todas as estatísticas, mas eles [os agentes] não sabiam disso [...] Agora, estão mais informados do que fazem. É menos incômodo. Assim mesmo, era possível saber, por meio da posição".

A relação entre a chefia e as operadoras obteve um ganho de franqueza, visto que os dois parceiros da relação partilham o conhecimento sobre o estado do saber do outro.

Nesse centro, com efeito, chega-se a uma situação que pode parecer paradoxal, situação em que o rendimento individual prevalece somente na medida em que contribui para o resultado coletivo. Com efeito, operadoras de alto "desempenho" podem ser levadas a abaixar seu ritmo de trbalho. A chefia assegura, nesse caso, uma função de coesão do grupo.

(II) Uma discussão com Christophe, encarregado, e uma operadora, Tania, vinda do primeiro centro, tem lugar no corredor, diante do painel da evolução dos resultados do último ano (efetivos, tráfego, etc.).

Christophe: "Sabia que ontem você ultrapassou a meta?" Tania: "O senhor sempre me dá números gerais?" Christophe: "27 segundos em média [de duração média da comunicação]". (Após o retorno da operadora na sala, ele me dirá que ela fez 560 chamadas no dia, as mais fracas fazem 134 chamadas por dia, ao passo que a média das operadoras atinge entre 200 e 300 chamadas por dia).

${ }^{17}$ Com o antigo sistema, as operadoras podiam empregar um código pessoal (que permitia identificar estatisticamente 0 agente) para acionar a $A V O$ (assistência vocal), mas isso não era obrigatório. Ao passo que, com o novo sistema, o uso desse código é imperativo para se poder responder às chamadas.
Tania: "Eu sempre trabalhei assim, estou acostumada com isso".

Tania: "[indo embora, um pouco incomodada] E isso não é ruim em relação às outras... [ela enrubece, hesita em terminar a frase]... Eu quero dizer o seguinte: será que não estou atrapalhando o resultado global?"

Christophe: "Não, de jeito nenhum. Além disso, eu sei que, com você, os clientes vão ter boas informações. [Em seguida, ele se volta para mim:] E eu tenho certeza que ela dá boas informações. Não recebo reclamações”. 
Em comparação com outros centros, o segundo centro ocupa um lugar particular no que respeita ao gerenciamento da chefia da divisão do trabalho entre as operadoras e a inscrição dessa particularidade nas relações hierárquicas. Nesse centro, o serviço prestado é o resultado da forma de cooperação entre as operadoras, maneira de trabalhar importada do domínio técnico, mas também resposta específica a um pessoal heterogêneo, em parte de origem operária e não familiarizado com esse tipo de atividade. Preservar uma certa autonomia do pessoal com respeito à divisão do trabalho era uma maneira de criar as condições de uma transmissão de conhecimentos entre o pessoal (principalmente por aqueles e aquelas que já conhecem a atividade, oriundos da região parisiense, como Tania), mas também para permitir que os agentes mudassem gradualmente de atividade. Entretanto, no contex to das transformações mais globais que afetam a atividade, não é certo que, como fundamento do serviço prestado, essa forma de colaboração possa sobreviver para além de um período de adaptação.

Assim, segundo os centros, é variável a importância do rendimento nas relações hierárquicas entre a chefia e as operadoras. Em certos centros, o rendimento individual ocupa um lugar central (I); em outros, o rendimento individual não faz parte dos meios de gerenciamento do pessoal utilizado (II).

O modo de intervenção da chefia na divisão do trabalho e suas definições do rendimento andam juntos; isso quer dizer que nos centros em que a chefia preconiza uma divisão técnica do trabalho, deixando pouca margem para adaptação à prescrição técnica do conteúdo do posto de trabalho pela pessoa que o ocupa, o rendimento individual das pessoas é um importante meio de gerenciamento. A partir do momento em que a chefia percebe o serviço como invariável, ela define sua função em relação à organização de uma concorrência entre os agentes em torno de seu rendimento.

O peso da chefia difere de um centro para outro devido às maneiras de intervir na organização global do trabalho e ao modo de definição e utilização da "produtividade" implementado, independentemente da conjuntura institucional e do dispositivo técnico comuns. Em certos casos, com efeito, a hierarquia parece limitar a autonomia das operadoras na divisão do trabalho, assim como no que respeita à extensão do serviço prestado ao utilizador, através dos modos de avaliação dos agentes segundo o número de chamadas atendidas.

De um centro a outro, a definição coletiva da "produtividade" diverge: no primeiro caso, ela é socialmente construída pela chefia como o resultado mensurável da relação das operadoras individuais com o trabalho (I); no segundo caso, a produtividade é definida inclusive pela chefia, e não somente pelas operadoras, como um conjunto de tarefas mais amplas, compreendendo a transmissão coletiva do savoir-faire entre os agentes (II). Tais definições coletivas da produtividade (pela chefia e pelas operadoras) influenciam a extensão das tarefas que podem ser realizadas pelas operadoras e influenciam, portanto, o serviço prestado. É do tipo do centro que dependem as 
possibilidades de que elas dispõem, ou não, de afirmar seu ponto de vista na relação com o cliente, isto é, de se fazer valer por ocasião da interação e, por conseguinte, sua maneira de definir o conteúdo do trabalho.

\section{Condusão}

Mostrou-se, portanto, que várias definições da produtividade podem coexistir no interior da mesma atividade de serviço: uma concepção "universalista" da produtividade, a veiculada por gerentes e pela chefia dos centros do primeiro tipo, e uma concepção coletiva da produtividade, a veiculada pelos coletivos de operadoras e pela chefia nos centros do segundo tipo. Na prática, portanto, a concepção local da produtividade, veiculada pelo coletivo das operadoras em interação com a encarregada, pode divergir da concepção veiculada pelos gerentes, a inscrita no dispositivo técnico. Portanto, a forma social de automação atual, mesmo se esta última define as condições da divisão e do conteúdo do trabalho, não a determina completamente: o conteúdo do trabalho das operadoras pode variar de um centro para o outro, assim como o serviço prestado. Logo, não há nem determinismo técnico do trabalho, nem da produtividade nessa atividade de serviço, apesar de tudo o que se pode ouvir a respeito do poder de vigilância das novas tecnologias neste domínio.

Em compensação, nada foi dito sobre a inscrição dessas diferenças no tempo: o trabalho de "ajuste" na passagem de um para outro nível de serviço, o que implica um crescimento e uma complicação das tarefas de tradução efetuadas, é temporariamente realizado pelas operadoras. Ora elas passam menos tempo para prestar um serviço equivalente, ora elas modificam o serviço prestado. Esse período de aprendizado dos utilizadores de novas formas de comportamento - apresentação de uma demanda padronizada e conforme à prescrição técnica - coincide com uma atenção particular da chefia dedicada à produtividade, definida como rendimento individual. Tudo então se conjuga para exercer uma pressão sobre as operadoras, visando à redução de sua autonomia em matéria de definição de produtividade.

Para além do estudo de um caso particular, o que a análise nos ensina a respeito da construção social da produtividade no interior de uma atividade de serviço? Num primeiro momento, foi possível mostrar que a organização sócio-técnica do trabalho não tem um caráter mais determinante que qualquer outra atividade de produção material. Em compensação, a técnica participa da construção social da produtividade. Num segundo momento, entretanto, analisar a produtividade de uma atividade de serviço implica igualmente um estudo da relação das pessoas em interação - diferentes categorias hierárquicas do pessoal no interior da empresa, mas igualmente entre o pessoal de execução e o utilizador do serviço. Em nosso caso, as operadoras de 
telefone estabeleceram uma relação não-mercantil de longa data com o utilizador: essa relação de auxílio mútuo lhes proporciona satisfações sociais - de prestar serviço - que se tornaram parte integrante de seu relacionamento com o trabalho. Modificar essa relação implica, portanto, uma modificação do relacionamento com o trabalho. Ora, o outro aspecto desse relacionamento com o trabalho, isto é, as relações hierárquicas, se caracterizam historicamente pela ausência de reconhecimento do savoir-faire das operadoras. Assim, as transformações da produtividade de uma atividade de serviço implicam uma perturbação do frágil equilíbrio entre as diferentes relações em interação - e as relações sociais em que se baseiam.

Recebido para publicação em fevereiro/2002

Tradução: Sílvio Rosa Filho

GEORGES, Isabel. Relationships with productivity: the case of the telephone information services. Tempo Social; Rev. Sociol. USP, S. Paulo, 14(1): 103-120, May 2002.

KEY WORDS:

work, services, productivity.

ABSTRACT: The article discusses the construction of the notion of productivity in the system of telephone information services in France. In order to do so, it looks at the present technical and spatial reorganization of the service, the formalization of its activities, the administrative practices of the people in charge, and the operators' work practices, confronting different possibilities of definition of the services delivered, and thus, their productivity.

\section{REFERÊNCIAS BIBLIOGRÁFICAS}

AKrich, Madeleine. (1990) De la sociologie des techniques à une sociologie des usagers. Technique et Culture, 16: 83-110.

Alonzo, Philippe. (1998) Les rapports au travail et à l'emploi des caissières de la grande distribution, des petites stratégies pour une grande vertu. Travail et Emploi, 3(76): 37-51.

Braverman, Harry. (1974) Labour and monopoly capital: the degradation of work in the Twentieth Century. New York, Montly Review Press.

Charron, Elsie. (1995) Une nouvelle catégorie professionnelle et ses métamorphoses, l' 'animateur' ouvrier et ses métamorphoses. Genèses, 20: 95-115, septembre. 
De Montmollin, Maurice \& Pastre, Olivier (Éds.). (1984) Le taylorisme. Paris, Édition de la Découverte.

FREYSSENET, Michel. (1984) La requalification des opérateurs et la forme sociale actuelle d'automatisation. Sociologie du travail, 4: 422-433.

- (1990) Les techniques productives sont-elles prescriptives? L'exemple des systèmes experts en entreprise. Cahier du GIP Mutations Industrielles, 45.

(1992) Processus et formes sociales d'automatisation. Le paradigme sociologique. Sociologie du travail, 4: 469-497.

GADREY, Jean. (1994) Les relations de service et d'analyse du travail des agents. Sociologie du travail, 3: 381-389.

(1996) L'économie des services. Paris, La Découverte.

Georges, Isabel. (1995) Les transformations du métier d'operatrice du téléphone à Paris et à Berlin après 1945. Université Paris VIII, École des Hautes Études en Sciences Sociales, École Normale Supérieure de Fontenay Saint-Cloud.

- (2000a) Travail et trajectoires de femmes dans des emplois de télécommunications en France et en Allemagne. Université de Paris VIII.

. (2000b) Les définitions sociales de la productivité. Les opératrices des renseignements téléphoniques. Cahiers $d u$ Centre de Recherches Historiques, 25: 67-80, octobre.

. (2001) Les emplois d'exécution dans les télécommunications: comparaisons France-Allemagne. Travail, Genre et Sociétés, 6: 143164 , octobre.

Grafmeyer, Yves. (1992) Les gens de la banque. Paris, PUF.

Maurice, Marc. (1980) Les déterminisme sociologique dans la sociologie du travail (1955-1980). Un changement de paradigme? Sociologie $d u$ Travail, 1: 22-37.

Noble, David F. (1978) Social choice in machine design: the case of automatically controlled machine tools, and a challenge for labor. Politics and Society, 8(3-4): 313-347.

Stroobants, Marcelle. (1991) Travail et compétence: récapitulation critique des approches des savoirs au travail. Formation et Emploi, 33: 3142, janvier-mars.

Terssac, Gilbert de. (1992) Autonomie dans le travail. Paris, PUF.

VERDIER, Eric. (1980) Traits spécifiques de l'informatisation du travail bancaire. Critique de l'Économie Politique, 12, juillet-septembre. 